\title{
A comparative analysis of VIKOR method and its variants
}

\author{
Prasenjit Chatterjee $^{\mathrm{a}}$ and Shankar Chakraborty ${ }^{\mathrm{b}^{*}}$
}

${ }^{a}$ Mechanical Engineering Department, MCKV Institute of Engineering, Howrah - 711 204, West Bengal, India ${ }^{b}$ Department of Production Engineering, Jadavpur University, Kolkata - 700 032, India

\section{H R O N I C L E}

\begin{tabular}{l}
\hline Article history: \\
Received February 25, 2016 \\
Received in revised format: \\
March 28, 2016 \\
Accepted May 19, 2016 \\
Available online \\
May 24 2016 \\
\hline Keywords: \\
VIKOR \\
Comprehensive VIKOR \\
Fuzzy VIKOR \\
Regret theory-based VIKOR \\
Modified VIKOR \\
Interval VIKOR \\
Rank
\end{tabular}

\section{Introduction}

Decision making is the act of identifying and choosing alternatives to find out the best solution from a pool of options based on different factors and considering the decision maker's expectations. Every decision is made within an environment, which is defined as the collection of information, alternatives, values and preferences available at the time when the decision must be made. The most difficult element in the decision making process is the multiplicity of criteria set for judging the alternatives. Thus, multicriteria decision making (MCDM) refers to making decisions in presence of multiple, usually conflicting criteria (beneficial and non-beneficial attributes). The MCDM problems are quite common in everyday life. The problem of decision making becomes more complex as different groups of decision makers are involved in the process. Although MCDM problems are widespread all the time, MCDM as a separate discipline only has a relatively short history of about 30 years. The development * Corresponding author.

E-mail address: s_chakraborty00@yahoo.co.in (S. Chakraborty)

C 2016 Growing Science Ltd. All rights reserved. doi: $10.5267 /$ j.dsl.2016.5.004

\begin{abstract}
The VIKOR (Vlse Kriterijumska Optimizacija Kompromisno Resenje which means multicriteria optimization and compromise solution, in Serbian) method has already become a quite popular multi-criteria decision making tool for its computational simplicity and solution determines compromise solution for a problem with conflicting criteria to help the decision maker in reaching a final course of action. It determines the compromise ranking list based on the particular measure of closeness to the ideal solution. Depending upon the type of decision it, like comprehensive VIKOR, fuzzy VIKOR, regret theory-based VIKOR, modified VIKOR and interval VIKOR methods have also been subsequently developed. In this paper, the ranking performance of original VIKOR method and its five variants is analyzed based on two demonstrative examples. It is observed that interval VIKOR method performs unsatisfactorily
and when the information in a decision problem is imprecise, fuzzy VIKOR method should always be preferred. But, for any decision problem, original VIKOR is the best method for solution without unnecessarily complicating the related mathematical computations.
\end{abstract}

(C) 2016 Growing Science Ltd. All rights reserved. 
of MCDM discipline is closely related to the rapid advancement of computer technology which makes it possible to conduct systematic analysis of complex MCDM problems. On the other hand, widespread use of information technology has generated a huge amount of information, which makes MCDM increasingly important and useful in supporting business decision making. The advantage of MCDM is that it provides a balanced view of how suitable any option is, and helps to take emotion out of the equation. It also stops any one factor from overshadowing others.

In general, there exist two distinct types of MCDM problems, e.g. the first type has a finite number of alternative solutions and the second one has an infinite number of solutions. Normally, in problems associated with selection and assessment, the number of alternative solutions is limited. An MCDM problem is usually described by a $m \times n$ decision matrix, where each element $a_{i j}$ denotes the performance of $i^{\text {th }}$ alternative with respect to $j^{\text {th }}$ criterion. Thus, to facilitate in arriving at the best course of action, a family of tools referred to as MCDM methods has emerged out due to the need to have a formalized technique to assist decision making in situations involving multiple criteria (Velasquez \& Hester, 2013). An MCDM method determines how attribute information is to be assessed to reach an appropriate selection. Given the decision matrix and an MCDM approach, the decision maker can now select the best alternative and/or rank the complete set of feasible alternatives. Till date, several MCDM methods have been proposed and successfully deployed to solve complex decision making problems arising from different corners of engineering and management. Amongst those techniques, VIKOR (the Serbian name is 'Vlse Kriterijumska Optimizacija Kompromisno Resenje' which means multi-criteria optimization and compromise solution) method has gained much popularity among the decision making community due to its simple and easily comprehensible computational steps (Opricovic \& Tzeng, 2004). The basic concept of VIKOR method lies in defining the positive and the negative ideal points in the solution space. It focuses on ranking and selecting from a finite set of feasible alternatives in presence of conflicting and non-commensurable (attributes with different units) criteria. It evaluates a multi-criteria ranking index based on the 'closeness' to the 'ideal' solution. When each alternative is evaluated with respect to each criterion, the compromise ranking can be obtained while comparing the relative closeness measure to the ideal alternative. Thus, the derived compromise solution is a feasible solution, which is the closest to the positive ideal solution and farthest from the negative ideal solution, and a compromise means an agreement established by mutual concessions made between the alternatives (Yazdani \& Graeml, 2014; Mardani et al., 2016). Along with the successful deployment of VIKOR method for solving complex decision making problems, other variants of it, like comprehensive VIKOR, fuzzy VIKOR, regret theory-based VIKOR, modified VIKOR and interval VIKOR methods have come into picture depending on the type of the decision problem and requirements of the concerned decision maker. They have been applied in different decision making scenarios, and have typical characteristics and mathematical formulations. There exists a great opportunity to compare the ranking performance of these five variants of VIKOR method with that of their original counterpart. The main focus of this paper is thus oriented towards comparing the ranking performance of all the six types of VIKOR method while solving two demonstrative examples. It is also attempted to identify the best performing VIKOR method using Spearman's rank correlation coefficient values.

\section{VIKOR method and its variants}

The mathematical formulations and procedural steps of the original VIKOR method and its five variants are detailed out here-in-under.

\subsection{VIKOR method}

The application of VIKOR method starts with the development of the corresponding evaluation or decision matrix which shows the performance of the alternatives with respect to various criteria. Let, $f_{i j}$ represents the performance measure of $i^{\text {th }}$ alternative with respect to $j^{\text {th }}$ criterion. The multi-criteria 
measure for compromise ranking is then developed from the $L_{p}$-metric used as an aggregating function in a compromise programming method (Zeleny, 1982).

$$
L_{p, i}=\left\{\sum_{j=1}^{M}\left(w_{j}\left[\left(f_{i j}\right)_{\max }-f_{i j}\right] /\left[\left(f_{i j}\right)_{\max }-\left(f_{i j}\right)_{\min }\right]\right)^{p}\right\}^{1 / p}, 1 \leq p \leq \infty ; i=1,2, \ldots, N
$$

where $M$ is the number of criteria $N$ is the number of alternatives and $w_{j}$ is the relative importance (weight) of $j^{\text {th }}$ criterion. In VIKOR method, $L_{1, i}$ and $L_{\infty, i}$ are used to formulate the ranking measure. The adoption of VIKOR method involves the following procedural steps:

a) From the given decision matrix, identify the best, $\left(f_{i j}\right)_{\max }$ and the worst, $\left(f_{i j}\right)_{\min }$ values of all the criteria.

b) The weights of the criteria are determined using analytic hierarchy process or entropy method.

c) Compute the values of $S_{i}$ and $R_{i}$ using the following equations:

$$
\begin{aligned}
& S_{i}=L_{1, i}=\sum_{j=1}^{M} w_{j}\left[\left(f_{i j}\right)_{\max }-f_{i j}\right] /\left[\left(f_{i j}\right)_{\max }-\left(f_{i j}\right)_{\min }\right] \\
& \left.\left.R_{i}=L_{\infty, i}=\operatorname{Max}\left\{w_{j} \mid\left(f_{i j}\right)_{\max }-f_{i j}\right] /\left(f_{i j}\right)_{\max }-\left(f_{i j}\right)_{\min }\right]\right\}, j=1,2, \ldots, M
\end{aligned}
$$

For beneficial criteria always requiring higher values, Eq. (2) is applicable. But for non-beneficial criteria desiring lower values, the term $\left[\left(f_{i j}\right)_{\max }-f_{i j}\right]$ in Eq. (2) is to be replaced by $\left[f_{i j}-\left(f_{i j}\right)_{\min }\right]$. Hence, for non-beneficial criteria, Eq. (2) can be reformulated as:

$$
S_{i}=L_{1, i}=\sum_{j=1}^{M} w_{j}\left[\left(f_{i j}\right)-\left(f_{i j}\right)_{\min }\right] /\left[\left(f_{i j}\right)_{\max }-\left(f_{i j}\right)_{\min }\right]
$$

d) Calculate $Q_{i}$ value.

$$
Q_{i}=v\left(\left(S_{i}-S_{i-\min }\right) /\left(S_{i-\max }-S_{i-\min }\right)\right)+(1-v)\left(\left(R_{i}-R_{i-\min }\right) /\left(R_{i-\max }-R_{i-\min }\right)\right),
$$

where $S_{i \text {-max }}$ and $S_{i \text {-min }}$ are the maximum and minimum values of $S_{i}$ respectively, and $R_{i \text {-max }}$ and $R_{i \text {-min }}$ are the maximum and minimum values of $R_{i}$ respectively. $v$ is introduced as weight of the strategy of 'the majority of attributes' (or 'the maximum group utility'). Its value lies between 0 and 1 . Usually, the value of $v$ as 0.5 is preferred. The compromise can be selected with 'voting by majority' $(v>0.5)$, with 'consensus' $(v=0.5)$ or with 'veto' $(v<0.5)$. More specifically, when $v$ equals unity, it represents a decision making process that can use the strategy of maximizing group utility, whereas when $v$ is zero, it represents a process that can use a minimum individual regret strategy that is found among maximum individual regrets/gaps of lower level criteria for each alternative. The value of $v$ affects the ranking of the alternatives and is usually determined externally by the decision expert.

e) Arrange the alternatives in ascending order, according to the values of $S, R$ and $Q$. It provides three ranking lists. In the ranking list derived based on the ascending values of $Q, a^{\prime}$ is the compromise solution (with minimum $Q$ value) if the following two conditions are satisfied:

C1: ‘Acceptable advantage’

$Q\left(a^{\prime \prime}\right)-Q\left(a^{\prime}\right) \geq \mathrm{DQ}$

where $a^{\prime \prime}$ is the second best alternative in the ranking list by $Q$ and $\mathrm{DQ}=1 /(N-1)$. 
C2 : 'Acceptable stability in decision making'

Alternative $a^{\prime}$ must also be the best ranked by $S$ or/and $R$.

If any one of the above-mentioned conditions is not satisfied, then a set of compromise solutions is proposed as follows:

- Alternatives $a^{\prime}$ and $a^{\prime \prime}$ if only condition C2 is not satisfied, or

- Alternatives $a^{\prime}, a^{\prime \prime}, \ldots, a^{(N)}$ if condition $\mathrm{C} 1$ is not satisfied, and $a^{(N)}$ is determined by the relation $\mathrm{Q}\left(a^{(N)}\right)-\mathrm{Q}\left(a^{\prime}\right)<\mathrm{DQ}$ for maximum $N$.

The VIKOR method is an effective MCDM tool, particularly when the decision maker is not able, or does not know to express his/her preference at the beginning of system design (Chatterjee et al., 2009; San Cristóbal, 2011; Anojkumar et al., 2014). The obtained compromise solution can be accepted because it provides a maximum 'group utility' of the 'majority', and a minimum of the individual regret of the 'opponent'. The compromise solutions can be the basis for negotiations, involving the decision maker's preference on criteria weights. In VIKOR method, the performance ratings of the alternatives with respect to a set of criteria are quantified as crisp values. But, under many circumstances, crisp data are inadequate to model real life situations. In addition, in case of conflicting situations or criteria, the decision maker must also consider imprecise or ambiguous data.

\subsection{Comprehensive VIKOR method}

The comprehensive VIKOR method was proposed by Jahan et al. (2011) for application to those situations where approaching the target values for some of the criteria are desirable. This new version of VIKOR method covers all types of criteria with emphasize on compromise solution. It thus overcomes the main error of the original VIKOR method. The procedural steps of comprehensive VIKOR method are enlisted as below (Bahraminasab \& Jahan, 2011; Cavallini et al., 2013):

a) Determine the most favorable values for all criteria.

$T=\left\{T_{1}, T_{2}, T_{3}, \ldots, T_{j}, \ldots, T_{n}\right\}=\left\{\right.$ Most desirable element $\left(r_{i j}\right)$ or target value for $j^{\text {th }}$ criterion $\}$,

where $r_{i j}(i=1,2, \ldots, m$ and $j=1,2, \ldots, n)$ are elements of the decision matrix (performance of $i^{\text {th }}$ alternative with respect to $j^{\text {th }}$ criterion).

b) Compute $S_{i}$ and $R_{i}$ values employing the following relations:

$$
S_{i}=\sum_{j=1}^{n} w_{j}\left(1-e^{\frac{\left|r_{i j}-T_{j}\right|}{-A_{j}}}\right), R_{i}=\operatorname{Max}_{j}\left[w_{j}\left(1-e^{\frac{\left|r_{i j}-T_{j}\right|}{-A_{j}}}\right)\right]
$$

where $A_{j}=\left\{1\right.$ if elements of $j^{\text {th }}$ criterion are normalized between 0 and $1, \max \left\{r_{j}^{\max }, T_{j}\right\}-\min \left\{r_{j}^{\min }, T_{j}\right.$ \}otherwise. $r_{j}^{\max }$ and $r_{j}^{\min }$ are the maximum and minimum elements in $j^{\text {th }}$ criterion respectively.

c) Compute the index value $Q_{i}$ as follows:

$$
Q_{i}=\left\{\begin{array}{l}
{\left[\frac{R_{i}-R^{-}}{R^{+}-R^{-}}\right] \text {if } S^{+}=S^{-}} \\
{\left[\frac{S_{i}-S^{-}}{S^{+}-S^{-}}\right] \text {if } R^{+}=R^{-}} \\
{\left[\frac{S_{i}-S^{-}}{S^{+}-S^{-}}\right] v+\left[\frac{R_{i}-R^{-}}{R^{+}-R^{-}}\right](1-v) \text { otherwise. }}
\end{array}\right.
$$


where $S^{-}=\operatorname{Min} S_{i}, S^{+}=\operatorname{Max} S_{i}, R^{-}=\operatorname{Min} R_{i}, R^{+}=\operatorname{Max} R_{i}$ and $v$ is introduced as a weight for the strategy of 'the majority of criteria' (or 'the maximum group utility'), whereas, $(1-v)$ is the weight of the individual regret. The remaining steps of comprehensive VIKOR method are same as those of the original VIKOR method.

\subsection{Fuzzy VIKOR method}

The fuzzy VIKOR method was proposed to solve multi-criteria decision making problems having fuzzy and imprecise data (Opricovic, 2011). It starts with the following decision matrix:

$$
\begin{aligned}
\widetilde{A} & =\left[\begin{array}{cccc}
\widetilde{x}_{11} & \widetilde{x}_{12} & \ldots & \widetilde{x}_{1 n} \\
\widetilde{x}_{21} & \widetilde{x}_{22} & \ldots & \widetilde{x}_{2 n} \\
\ldots & \ldots & \ldots & \ldots \\
\widetilde{x}_{m 1} & \widetilde{x}_{m 2} & \ldots & \widetilde{x}_{m n}
\end{array}\right]=\left[\widetilde{x}_{i j}\right]_{m \times n} \\
\widetilde{w} & =\left[\widetilde{w}_{1}, \widetilde{w}_{2}, \ldots, \widetilde{w}_{n}\right]
\end{aligned}
$$

where $\tilde{x}_{i j}, \forall i, j$ is the fuzzy rating (fuzzy performance value) of $i^{\text {th }}$ alternative with respect to $j^{\text {th }}$ criterion and $\widetilde{w}_{j}$ is the fuzzy weight of $j^{\text {th }}$ criterion expressing the decision maker's preference as the relative importance of the criterion. It is usually assumed that the alternatives are evaluated using triangular fuzzy numbers, $\widetilde{f}_{i j}=\left(l_{i j}, m_{i j}, r_{i j}\right)$. The set of beneficial criteria (higher the better) is expressed as $I^{b}$, whereas, $I^{c}$ denotes the set of non-beneficial criteria (lower the better). Now, fuzzy VIKOR method can be applied employing the following procedural steps (Kuo \& Liang, 2011; Jeya Girubha \& Vinodh, 2012):

a) Determine the positive ideal, $\widetilde{f}_{i}^{*}=\left(l_{i}^{*}, m_{i}^{*}, r_{i}^{*}\right)$ and the negative ideal, $\widetilde{f}_{i}^{\circ}=\left(l_{i}^{\circ}, m_{i}^{\circ}, r_{i}^{\circ}\right)$ values of all the criteria.

$$
\begin{array}{lll}
\widetilde{f}_{i}^{*}=\operatorname{Max}\left(\widetilde{f}_{i j}\right), & \widetilde{f}_{i}^{\circ}=\operatorname{Min}\left(\widetilde{f}_{i j}\right), & \text { for } i \in I^{b} ; \\
\widetilde{f}_{i}^{*}=\operatorname{Min}\left(\widetilde{f}_{i j}\right), & \widetilde{f}_{i}^{\circ}=\operatorname{Max}\left(\widetilde{f}_{i j}\right), & \text { for } i \in I^{c} .
\end{array}
$$

b) Compute the value of normalized fuzzy difference, $\tilde{d}_{i j}(i=1,2, \ldots, n ; j=1,2, \ldots, J)$.

$$
\begin{array}{ll}
\widetilde{d}_{i j}=\left(\widetilde{f}_{i}^{*}-\widetilde{f}_{i j}\right) /\left(r_{i}^{*}-l_{i}^{\circ}\right), & \text { for } i \in I^{b} ; \\
\widetilde{d}_{i j}=\left(\widetilde{f}_{i j}-\widetilde{f}_{i}^{*}\right) /\left(r_{i}^{\circ}-l_{i}^{*}\right), & \text { for } i \in I^{c} .
\end{array}
$$

c) Determine $\widetilde{S}_{j}=\left(S_{j}^{l}, S_{j}^{m}, S_{j}^{r}\right)$ and $\widetilde{R}_{j}=\left(R_{j}^{l}, R_{j}^{m}, R_{j}^{r}\right)$ (for $\left.j=1,2, \ldots, J\right)$ using the following equations:

$$
\begin{aligned}
& \widetilde{S}_{j}=\sum_{i=1}^{n} \oplus\left(\widetilde{w}_{i} \otimes \widetilde{d}_{i j}\right) \\
& \widetilde{R}_{j}=\operatorname{Max}_{i}\left(\widetilde{w}_{i} \otimes \widetilde{d}_{i j}\right)
\end{aligned}
$$

where $\widetilde{S}$ is a fuzzy weighted sum and $\widetilde{R}$ is a fuzzy operator MAX.

d) Compute $\widetilde{Q}_{j}=\left(Q_{j}^{l}, Q_{j}^{m}, Q_{j}^{r}\right)$ (for $\left.j=1,2, \ldots, J\right)$ applying the following expression:

$$
\widetilde{Q}_{j}=v\left(\widetilde{S}_{j}-\widetilde{S}^{*}\right) /\left(S^{\circ r}-S^{* l}\right) \oplus(1-v)\left(\widetilde{R}_{j}-\widetilde{R}^{*}\right) /\left(R^{\circ r}-R^{* l}\right)
$$

where $\widetilde{S}^{*}=\operatorname{Min}_{j} \widetilde{S}_{j}, S^{\circ r}=\max _{j} S_{j}^{r}, \widetilde{R}^{*}=\operatorname{Min}_{j} \widetilde{R}_{j}, R^{\circ r}=\max _{j} R_{j}^{r}$.

e) Perform the preliminary (core) ranking. 
Rank the alternatives by sorting the core values $Q_{j}^{m}$ (for $\left.j=1,2, \ldots, J\right)$ in decreasing order. The obtained rank ordering is denoted by $\{A\}_{Q^{m}}$.

f) Perform fuzzy ranking.

The $j^{\text {th }}$ ranking position in $\{A\}_{Q^{m}}$ of an alternative $A^{(j)}($ for $j=1,2, \ldots, J)$ is confirmed if $\underset{k \in J^{j}}{\operatorname{Min}} \widetilde{Q}^{(k)}=\widetilde{Q}^{(j)}$, where $j^{j}=\{j, j+1, \ldots, J\}$ and $\widetilde{Q}^{(k)}$ is the fuzzy merit for alternative $A^{(k)}$ at $k^{\text {th }}$ position in $\{A\}_{Q^{m}}$.

g) Defuzzify $\widetilde{S}_{j}, \widetilde{R}_{j}$ and $\widetilde{Q}_{j}$ values.

h) Rank the alternatives, sorting by the crisp values $S, R$ and $Q$ in decreasing order. It results in three ranking lists $\{A\} S,\{A\} R$ and $\{A\} Q$.

i) The remaining steps of fuzzy VIKOR method are the same as step (e) of original VIKOR method.

\subsection{Regret theory-based VIKOR method}

In regret theory-based VIKOR method, regret theory is integrated with the original VIKOR method in order to take into account the notion of regret and rejoicing in the decision making process. In regret theory (Bell, 1982), it is assumed that humans' decision making is occasionally influenced by emotions. Emotions are changes in mental and psychological states, and are used to be thought as the one of the main reasons for triggering decision making. The main concept of regret theory is that the classical utility function is modified by incorporating the anticipated feelings of a decision maker (Mellers, 2000). It is assumed that the degree of regret or rejoicing of an individual depends only on the difference between the choiceless utility of what is and the choiceless utility of what might have been. The choiceless utility is the utility that an individual can derive from the consequence if he/she has experienced it without having chosen it and is defined independently of choices. The distinction between VIKOR method and regret theory is that VIKOR method defines regret as the difference between alternatives and the best value of each criterion, and regret theory defines regret as the choiceless utility. A regret-rejoicing function can be defined to modify the classical utility as follows:

$$
u_{i k}^{i}=u_{j i}+R\left(u_{j i}-u_{k i}\right) \text {, }
$$

where $u_{i j}^{k}$ denotes the modified utility of $j^{\text {th }}$ alternative with respect to $k^{\text {th }}$ alternative in $i^{\text {th }}$ criterion, $u_{j i}$ is the classic utility of $j^{\text {th }}$ alternative in $i^{\text {th }}$ criterion defined over outcomes, and $R($.$) denotes a regret-$ rejoicing function. Thus, for an MCDM problem, the modified utility for $j^{\text {th }}$ alternative as calculated based on regret theory can be presented as follows (Huang et al., 2009):

$$
U_{j}=\sum_{i=1}^{n} w_{i}\left[u_{j i}-\frac{1}{J-1} \sum_{j=1}^{J} R\left(f_{j i}-f_{k i}\right)\right],
$$

where $w_{i}$ denotes the weight of $i^{\text {th }}$ criterion and $J$ is the number of criteria.

From the above equation, it can be observed that the regret function is a regret-rejoicing function, since $R\left(f_{j i}-f_{k i}\right)$ may be larger than zero (i.e. rejoicing) or less than zero (i.e. regret). Thus, the degrees of regret and rejoicing are reflected by a singular function. In regret theory-based VIKOR model, the revised $S_{j}$ and $R_{j}$ values denote the choiceless and discontent utilities respectively, and can be defined as follows:

$$
\begin{aligned}
& S_{j}=\left\{\begin{array}{l}
\left\|\sum_{i=1}^{n} w_{i} \frac{1}{J-1} \sum_{k=1}^{J}\left(f_{k i}-f_{j i}\right)\right\|_{p} \quad \text { if } f_{j i}<f_{k i}, \\
0, \text { otherwise. }
\end{array}\right. \\
& R_{j}=\left\|\sum_{i=1}^{n} w_{i}\left(f_{i}^{*}-f_{j i}\right)\right\|_{p},
\end{aligned}
$$


where \|\|$_{p}$ denotes the $L_{p}$-norm. In this equation, $L_{2}$-norm is used to calculate $S_{j}$ and $R_{j}$ values. The remaining procedural steps of regret theory-based VIKOR method to determine $Q_{j}$ values in order to achieve the ranking order of the alternatives are the same as the original VIKOR method.

\subsection{Modified VIKOR method}

The main difference between modified VIKOR and original VIKOR methods is the replacement of a fixed common number of criteria for all alternatives with a set of criteria for each alternative, and providing a method for ranking the unimproved gaps of alternatives (Liou et al., 2011). The application of modified VIKOR involves the following procedural steps:

a) Determine the best $f_{j}^{*}$ and the worst $f_{j}^{-}$values. Because each alternative is evaluated, not compared according to its own criteria, a positive ideal and a negative ideal point, as in VIKOR method, i.e. $f_{j}^{*}=\max f_{i j}$ and $f_{j}^{-}=\min f_{i j}$, cannot be used here. Therefore, the benefit or cost must be reset according to the expectation of the decision maker for each criterion of the alternatives; the best $f_{j}^{*}$ is the aspired level and the worst $f_{j}^{-}$is the tolerable level, these functions are expressed as follows:

$f_{j}^{*}=\operatorname{aspired} f_{i j}\left(\right.$ or $f_{j}^{*}=$ aspired_level)

$f_{j}^{-}=$tolerable $f_{i j}$ (or $f_{j}^{-}=$tolerable_level)

The normalized rating $r_{i j}$ is obtained using the following equation:

$$
r_{i j}=\left(\left|f_{j}^{*}-f_{i j}\right|\right) /\left(\left|f_{j}^{*}-f_{j}^{-}\right|\right)
$$

In addition, the normalized weight-rating is to be rewritten in a different way, where $n_{i}$ is the number of criteria in each alternative $A_{i}$ because each alternative has its own assessing criteria. The weights $w_{j}^{i}$ must be normalized under the same alternative $\left(j=1,2, \ldots, n_{i}\right)$, i.e. $\sum_{j=1}^{n_{i}} w_{j}^{i}=1$.

b) Compute $S_{i}$ and $Q_{i},(i=1,2, \ldots, m)$ values applying the following expressions:

$$
\begin{aligned}
S_{i} & =\sum_{j=1}^{n_{i}} w_{j}^{i} r_{i j}\left(i=1,2, \ldots, n_{i}\right) \\
Q_{i} & =\max \left\{r_{i j} \mid j=1,2, \ldots, n_{i}\right\}
\end{aligned}
$$

In VIKOR method, $Q_{i}$ is represented as $\max \left\{w_{j} r_{i j} j j=1,2, \ldots, n\right\}$ implying that group utility is more important than maximum regret. Because $Q_{i}$ is only a part of $S_{i}, S_{i}$ must exceed $Q_{i} . S_{i}$ is emphasized more than $Q_{i}$ in original VIKOR method. However, the maximum regret is often important in practice and is usually taken into account. To balance $S_{i}$ and $Q_{i}$, Eq. (22) is used instead of the traditional $Q_{i}$ in VIKOR method. Eq. (22) is used as showing the maximum gap to be improved.

c) Compute the index value $R_{i}(i=1,2, \ldots, m)$ as follows:

$$
R_{i}=v\left(S_{i}-S^{*}\right) /\left(S^{-}-S^{*}\right)+(1-v)\left(Q_{i}-Q^{*}\right) /\left(Q^{-}-Q^{*}\right),
$$

where $S^{*}=$ best $S, S^{-}=$worst $S, Q^{*}=$ best $Q, Q^{-}=$worst $Q$.

In original VIKOR method, $\bar{S}^{*}, S^{-}, Q^{*}$ and $Q^{-}$are set as $\bar{S}^{*}=\min S_{i}, S^{-}=\max S_{i}, Q^{*}=\min Q_{i}$ and $Q^{-}=$ $\max Q_{i}$. However, in modified VIKOR method, an aspired level and a tolerable level for $S$ and $Q$ of the compared alternatives are appended respectively to obtain absolute relations for the index values $R_{i}$. Here, the best $S^{*}=0$ and $Q^{*}=0$, and the worst $S^{-}=1$ and $Q^{-}=1$ are decided to obtain absolute relations 
for the index values $R_{i}$ and Eq. (23) can be rewritten as $R_{i}=v S_{i}+(1-v) Q_{i}$. Specifically, if min $S_{i}$ and min $Q_{i}$ are expressed as $S^{*}$ and $Q^{*}$ respectively, it implies a relative relation for the index relations $R_{i}$ of these alternatives, whereas, if a zero gap is used as the best level and unity as the worst, it implies an absolute relation for the index relations $R_{i}$ of these alternatives (Maji, 2012).

\subsection{Interval VIKOR method}

It has already been noticed that the interval numbers are more suitable to deal with decision making problems in imprecise and uncertain environment, because they are the simplest form of representing uncertainty in a decision matrix. The interval numbers require minimum amount of information about the attribute values. Specifying an interval for an attribute in decision matrix indicates that it can take any value within the interval. The interval numbers do not indicate how probable it is to the value to be in the interval, nor do it indicate which of the many values in the interval is the most likely to occur (Jahanshahloo et al., 2009). Thus, when determining the exact values of the attributes is difficult or impossible, it is more appropriate to consider them as interval numbers. In interval VIKOR method (Sayadi et al., 2009), the decision matrix with interval numbers is expressed in the following form:

$$
\left[\begin{array}{cccc}
{\left[f_{11}^{L}, f_{11}^{U}\right]} & {\left[f_{12}^{L}, f_{12}^{U}\right]} & \ldots & {\left[f_{1 n}^{L}, f_{1 n}^{U}\right]} \\
{\left[f_{21}^{L}, f_{21}^{U}\right]} & {\left[f_{22}^{L}, f_{22}^{U}\right]} & \ldots & {\left[f_{2 n}^{L}, f_{2 n}^{U}\right]} \\
\ldots & \ldots & \ldots & \ldots \\
{\left[f_{m 1}^{L}, f_{m 1}^{U}\right]} & {\left[f_{m 2}^{L}, f_{m 2}^{U}\right]} & \ldots & {\left[f_{m n}^{L}, f_{m n}^{U}\right]}
\end{array}\right]
$$

The performance of $i^{\text {th }}$ alternative with respect to $j^{\text {th }}$ criterion is not known exactly and only $f_{i j} \in\left[f_{i j}^{L}, f_{i j}^{U}\right]$ is known. The application of interval VIKOR method consists of the following sequential steps:

a) Determine the positive ideal and the negative ideal solutions.

$$
\begin{aligned}
& A^{*}=\left\{f_{1}^{*}, f_{2}^{*}, \ldots, f_{n}^{*}\right\}=\left\{\left(\max f_{i j}^{U} \mid j \in I\right) \operatorname{or}\left(\min f_{i j}^{L} \mid j \in J\right)\right\} j=1,2, \ldots, n \\
& A^{-}=\left\{f_{1}^{-}, f_{2}^{-}, \ldots, f_{n}^{-}\right\}=\left\{\left(\min f_{i j}^{L} \mid j \in I\right) \operatorname{or}\left(\max f_{i j}^{U} \mid j \in J\right)\right\} j=1,2, \ldots, n
\end{aligned}
$$

where $I$ is the number of beneficial criteria and $J$ is the number of non-beneficial criteria.

b) Determine $\left[S_{i}^{L}, S_{i}^{U}\right]$ and $\left[R_{i}^{L}, R_{i}^{U}\right]$.

$$
\begin{aligned}
& S_{i}^{L}=\sum_{j \in I} w_{j}\left(\frac{f_{j}^{*}-f_{i j}^{U}}{f_{j}^{*}-f_{j}^{-}}\right)+\sum_{j \in J} w_{j}\left(\frac{f_{i j}^{L}-f_{j}^{*}}{f_{j}^{-}-f_{j}^{*}}\right) i=1,2, \ldots m \\
& S_{i}^{U}=\sum_{j \in I} w_{j}\left(\frac{f_{j}^{*}-f_{i j}^{L}}{f_{j}^{*}-f_{j}^{-}}\right)+\sum_{j \in J} w_{j}\left(\frac{f_{i j}^{U}-f_{j}^{*}}{f_{j}^{-}-f_{j}^{*}}\right) i=1,2, \ldots m \\
& R_{i}^{L}=\max \left\{w_{j}\left(\frac{f_{j}^{*}-f_{i j}^{U}}{f_{j}^{*}-f_{j}^{-}}\right) j \in I, w_{j}\left(\frac{f_{i j}^{L}-f_{j}^{*}}{f_{j}^{-}-f_{j}^{*}}\right) j \in J\right\} i=1,2, \ldots, m \\
& R_{i}^{U}=\min \left\{w_{j}\left(\frac{f_{j}^{*}-f_{i j}^{L}}{f_{j}^{*}-f_{j}^{-}}\right) j \in I, w_{j}\left(\frac{f_{i j}^{U}-f_{j}^{*}}{f_{j}^{-}-f_{j}^{*}}\right) j \in J\right\} i=1,2, \ldots, m
\end{aligned}
$$

c) Compute the interval $Q_{i}=\left[Q_{i}^{L}, Q_{i}^{U}\right]$.

$$
\begin{aligned}
& Q_{i}^{L}=v \frac{\left(S_{i}^{L}-S^{*}\right)}{\left(S^{-}-S^{*}\right)}+(1-v) \frac{\left(R_{i}^{L}-R^{*}\right)}{\left(R^{-}-R^{*}\right)} \\
& Q_{i}^{U}=v \frac{\left(S_{i}^{U}-S^{*}\right)}{\left(S^{-}-S^{*}\right)}+(1-v) \frac{\left(R_{i}^{U}-R^{*}\right)}{\left(R^{-}-R^{*}\right)}
\end{aligned}
$$

where $S^{*}=\min S_{i}^{L}, S^{-}=\max S_{i}^{U}, R^{*}=\min R_{i}^{L}$ and $R^{-}=\max R_{i}^{U}$. 
d) In original VIKOR method, the alternative that has the minimum $Q_{i}$ is the best option and it is chosen as the compromise solution. But in interval VIKOR method, $Q_{i}$ values as calculated using Eqs. (31-32) are expressed in interval numbers. To choose the minimum interval number, the $Q_{i}$ values are now compared with each other using a combined approach (Delgado et al., 1998; Sengupta \& Pal, 2000). In this approach, an interval $E$ is alternatively represented as $E=[m(E), w(E)]$, where $m(E)$ and $w(E)$ are the mid-point and half-width of the interval $E$, i.e. $m(E)=0.5 \times\left(e^{L}+e^{U}\right)$ and $w(E)=0.5 \times\left(e^{U}-e^{L}\right)$. After this representation, two interval numbers $E$ and $D$ can be ranked while comparing their mid-point values. In interval VIKOR method, a lower mid-point value indicates better position of an alternative in the ranking preorder.

\section{Illustrative examples}

In order to analyze the ranking performance of VIKOR method and its five variants, the following two examples are considered and subsequently solved.

\subsection{Example 1}

Maity and Chakraborty (2013) considered a set of eight grinding wheel abrasive materials and evaluated their performance based on seven criteria, i.e. Knoop hardness (in KHN) $\left(\mathrm{C}_{1}\right)$, modulus of elasticity (in $\mathrm{GPa})\left(\mathrm{C}_{2}\right)$, compressive strength (in $\left.\mathrm{MPa}\right)\left(\mathrm{C}_{3}\right)$, shear strength (in $\left.\mathrm{MPa}\right)\left(\mathrm{C}_{4}\right)$, thermal conductivity $(\mathrm{W} / \mathrm{mk})\left(\mathrm{C}_{5}\right)$, fracture toughness $\left(\mathrm{MPa}-\mathrm{m}^{1 / 2}\right)\left(\mathrm{C}_{6}\right)$ and material cost $(\mathrm{USD} / \mathrm{kg})\left(\mathrm{C}_{7}\right)$. All those criteria except the grinding wheel abrasive material cost are beneficial in nature where higher values are always preferred. Applying entropy method (Rao, 2007), the weights of those seven criteria were determined as $w_{\mathrm{C} 1}=0.3552, w_{\mathrm{C} 2}=0.0429, w_{\mathrm{C} 3}=0.4356, w_{\mathrm{C} 4}=0.1248, w_{\mathrm{C} 5}=0.01661, w_{\mathrm{C} 6}=$ 0.0001 and $w_{\mathrm{C} 7}=0.0252$. Fuzzy technique for order performance by similarity to ideal solution (FTOPSIS) was adopted to solve the grinding wheel abrasive material selection problem, and a complete ranking of the alternative abrasive materials was achieved as $A_{5}-A_{3}-A_{2}-A_{4}-A_{6}-A_{1}-A_{7}-A_{8}$. Synthetic polycrystal diamond, cubic boron nitride and tungsten carbide respectively obtained the first, second and third ranks. Yttria stabilized zirconia was the worst preferred grinding wheel abrasive material. The decision matrix for this grinding wheel abrasive material selection problem is shown in Table 1 which is subsequently solved employing the six different types of VIKOR method.

\section{Table 1}

Decision matrix for grinding wheel abrasive material selection problem (Maity \& Chakraborty, 2013)

\begin{tabular}{lccccccc}
\hline Alternative & \multicolumn{3}{c}{ Criteria } \\
\cline { 2 - 8 } & $\mathrm{C}_{1}$ & $\mathrm{C}_{2}$ & $\mathrm{C}_{3}$ & $\mathrm{C}_{4}$ & $\mathrm{C}_{5}$ & $\mathrm{C}_{6}$ & $\mathrm{C}_{7}$ \\
\hline Titanium carbide $\left(\mathrm{A}_{1}\right)$ & 3200 & 451 & 3475 & 756 & 17 & 4.15 & 18 \\
Tungsten carbide $\left(\mathrm{A}_{2}\right)$ & 2400 & 690 & 4975 & 1324 & 98 & 3 & 60 \\
Cubic boron nitride $\left(\mathrm{A}_{3}\right)$ & 5000 & 850 & 6900 & 1532 & 13 & 4.5 & 864 \\
Aluminum oxide $\left(\mathrm{A}_{4}\right)$ & 3000 & 400 & 3800 & 879 & 30 & 4 & 152 \\
Synthetic polycrystal diamond $\left(\mathrm{A}_{5}\right)$ & 8000 & 953 & 6700 & 4688 & 1200 & 8.6 & 1300 \\
Silicon carbide $\left(\mathrm{A}_{6}\right)$ & 2550 & 440 & 4600 & 480 & 200 & 3.1 & 10 \\
Boron carbide $\left(\mathrm{A}_{7}\right)$ & 2800 & 460 & 1721 & 600 & 90 & 2.5 & 50 \\
Yttria stabilized zirconia $\left(\mathrm{A}_{8}\right)$ & 1200 & 160 & 1750 & 620 & 2.2 & 8.2 & 45 \\
\hline
\end{tabular}

Now, this grinding wheel abrasive material selection problem is first solved using the original VIKOR method. The priority weights of the seven considered criteria as determined by Maity and Chakraborty (2013) are also employed here for the subsequent VIKOR method-based analyses. Table 2 shows the computed values of $S_{i}, R_{i}$ and $Q_{i}$ for the $v$ value of 0.5 , and when all the eight alternatives are arranged in ascending order of $Q_{i}$ values, the ranking preorder is attained as $\mathrm{A}_{5}-\mathrm{A}_{3}-\mathrm{A}_{2}-\mathrm{A}_{4}-\mathrm{A}_{6}-\mathrm{A}_{1}-\mathrm{A}_{7}-\mathrm{A}_{8}$. It is observed that this ranking order exactly corroborates with that obtained by Maity and Chakraborty (2013) while applying FTOPSIS method. Table 3 shows the changes in ranking patterns of the grinding wheel abrasive materials with varying $v$ values. The ranks of the alternative materials are shown in first brackets. It is observed from Table 3 that for all $v$ values, the ranking positions of the best two and the worst two material alternatives do not change. The ranking patterns of the alternatives are maximally 
stable for $v$ values of 0.5 and 0.6 . For other $v$ values, there are slight variations in the intermediate rankings of the alternatives.

Table 2

Ranking of material alternatives in VIKOR method

\begin{tabular}{ccccc}
\hline Alternative & $S_{i}$ & $R_{i}$ & $Q_{i}$ & Rank \\
\hline $\mathrm{A}_{1}$ & 0.7236 & 0.2881 & 0.6860 & 6 \\
$\mathrm{~A}_{2}$ & 0.6075 & 0.2925 & 0.6319 & 3 \\
$\mathrm{~A}_{3}$ & 0.2804 & 0.1567 & 0.3021 & 2 \\
$\mathrm{~A}_{4}$ & 0.7030 & 0.2612 & 0.6434 & 4 \\
$\mathrm{~A}_{5}$ & 0.0168 & 0.0168 & 0 & 1 \\
$\mathrm{~A}_{6}$ & 0.6694 & 0.2847 & 0.6542 & 5 \\
$\mathrm{~A}_{7}$ & 0.8946 & 0.4356 & 0.9498 & 7 \\
$\mathrm{~A}_{8}$ & 0.9925 & 0.4332 & 0.9971 & 8 \\
\hline
\end{tabular}

Table 3

Changes in rankings with varying $v$ values in VIKOR method

\begin{tabular}{|c|c|c|c|c|c|c|c|c|c|}
\hline Alternative & $v=0.1$ & $v=0.2$ & $v=0.3$ & $v=0.4$ & $v=0.5$ & $v=0.6$ & $v=0.7$ & $v=0.8$ & $v=0.9$ \\
\hline $\mathrm{A}_{1}$ & $\begin{array}{c}0.6554 \\
(6)\end{array}$ & $\begin{array}{c}0.6630 \\
(6)\end{array}$ & $\begin{array}{c}0.6707 \\
(6)\end{array}$ & $\begin{array}{c}0.6784 \\
(6)\end{array}$ & $\begin{array}{c}0.6860 \\
(6)\end{array}$ & $\begin{array}{c}0.6937 \\
(6)\end{array}$ & $\begin{array}{c}0.7014 \\
(6)\end{array}$ & $\begin{array}{c}0.7090 \\
(6)\end{array}$ & $\begin{array}{c}0.7167 \\
(6)\end{array}$ \\
\hline $\mathrm{A}_{2}$ & $\begin{array}{c}0.6530 \\
(5)\end{array}$ & $\begin{array}{c}0.6477 \\
(5)\end{array}$ & $\begin{array}{c}0.6425 \\
(4)\end{array}$ & $\begin{array}{c}0.6372 \\
\text { (4) }\end{array}$ & $\begin{array}{c}0.6319 \\
(3)\end{array}$ & $\begin{array}{c}0.6266 \\
(3)\end{array}$ & $\begin{array}{c}0.6213 \\
(3)\end{array}$ & $\begin{array}{c}0.6160 \\
(3)\end{array}$ & $\begin{array}{c}0.6107 \\
\text { (3) }\end{array}$ \\
\hline $\mathrm{A}_{3}$ & $\begin{array}{c}0.3276 \\
(2)\end{array}$ & $\begin{array}{c}0.3212 \\
(2)\end{array}$ & $\begin{array}{c}0.3149 \\
(2)\end{array}$ & $\begin{array}{c}0.3085 \\
\text { (2) }\end{array}$ & $\begin{array}{c}0.3021 \\
\text { (2) }\end{array}$ & $\begin{array}{c}0.2957 \\
(2)\end{array}$ & $\begin{array}{c}0.2893 \\
\text { (2) }\end{array}$ & $\begin{array}{c}0.2829 \\
(2)\end{array}$ & $\begin{array}{c}0.2765 \\
(2)\end{array}$ \\
\hline $\mathrm{A}_{4}$ & $\begin{array}{c}0.5955 \\
\text { (3) }\end{array}$ & $\begin{array}{c}0.6074 \\
\text { (3) }\end{array}$ & $\begin{array}{c}0.6194 \\
\text { (3) }\end{array}$ & $\begin{array}{c}0.6314 \\
\text { (3) }\end{array}$ & $\begin{array}{c}0.6434 \\
\text { (4) }\end{array}$ & $\begin{array}{c}0.6554 \\
\text { (4) }\end{array}$ & $\begin{array}{c}0.6673 \\
(5)\end{array}$ & $\begin{array}{c}0.6793 \\
(5)\end{array}$ & $\begin{array}{c}0.6913 \\
(5)\end{array}$ \\
\hline $\mathrm{A}_{5}$ & $0(1)$ & $0(1)$ & $0(1)$ & $0(1)$ & $0(1)$ & $0(1)$ & $0(1)$ & $0(1)$ & $0(1)$ \\
\hline $\mathrm{A}_{6}$ & $\begin{array}{c}0.6425 \\
(4)\end{array}$ & $\begin{array}{c}0.6455 \\
(4)\end{array}$ & $\begin{array}{c}0.6483 \\
(5)\end{array}$ & $\begin{array}{c}0.6513 \\
(5)\end{array}$ & $\begin{array}{c}0.6542 \\
\quad(5)\end{array}$ & $\begin{array}{c}0.6571 \\
(5)\end{array}$ & $\begin{array}{l}0.6601 \\
\text { (4) }\end{array}$ & $\begin{array}{c}0.6630 \\
(4)\end{array}$ & $\begin{array}{c}0.6659 \\
\text { (4) }\end{array}$ \\
\hline $\mathrm{A}_{7}$ & $\begin{array}{c}0.9900 \\
(7)\end{array}$ & $\begin{array}{c}0.9799 \\
(7)\end{array}$ & $\begin{array}{c}0.9699 \\
(7)\end{array}$ & $\begin{array}{c}0.9598 \\
(7)\end{array}$ & $\begin{array}{l}0.9498 \\
(7)\end{array}$ & $\begin{array}{c}0.9398 \\
(7)\end{array}$ & $\begin{array}{c}0.9297 \\
(7)\end{array}$ & $\begin{array}{c}0.9197 \\
(7)\end{array}$ & $\begin{array}{c}0.9096 \\
(7)\end{array}$ \\
\hline $\mathrm{A}_{8}$ & $\begin{array}{c}0.9948 \\
(8)\end{array}$ & $\begin{array}{c}0.9953 \\
(8)\end{array}$ & $\begin{array}{c}0.9959 \\
(8)\end{array}$ & $\begin{array}{c}0.9965 \\
(8)\end{array}$ & $\begin{array}{c}0.9971 \\
(8)\end{array}$ & $\begin{array}{c}0.9977 \\
(8)\end{array}$ & $\begin{array}{c}0.9982 \\
(8)\end{array}$ & $\begin{array}{c}0.9988 \\
(8)\end{array}$ & $\begin{array}{c}0.9994 \\
(8)\end{array}$ \\
\hline
\end{tabular}

In comprehensive VIKOR method, $S_{i}$ and $R_{i}$ values are first computed for all the considered material alternatives for a $v$ value of 0.5 and the corresponding $Q_{i}$ values are subsequently determined in Table 4. Now, based on the ascending values of $v$, the alternatives are ranked as $A_{5}-A_{3}-A_{2}-A_{6}-A_{4}-A_{1}-A_{7}-A_{8}$. In this method too, the best and the worst rankings of the alternatives do not change. Basically, the positions of the first three and the last three materials are the same when compared to the ranking pattern of VIKOR method. It is also observed that the positions of the best-ranked and the worst-ranked material alternatives remain unaffected with changing $v$ values, although there are some marginal variations in the intermediate ranking orders.

Table 4

Ranking of material alternatives in comprehensive VIKOR method

\begin{tabular}{ccccc}
\hline Alternative & $S_{i}$ & $R_{i}$ & $Q_{i}$ & Rank \\
\hline $\mathrm{A}_{1}$ & 0.4968 & 0.2108 & 0.7743 & 6 \\
$\mathrm{~A}_{2}$ & 0.4260 & 0.1993 & 0.6913 & 3 \\
$\mathrm{~A}_{3}$ & 0.2202 & 0.1267 & 0.3742 & 2 \\
$\mathrm{~A}_{4}$ & 0.4897 & 0.1962 & 0.7400 & 5 \\
$\mathrm{~A}_{5}$ & 0.0324 & 0.0165 & 0 & 1 \\
$\mathrm{~A}_{6}$ & 0.4605 & 0.1958 & 0.7143 & 4 \\
$\mathrm{~A}_{7}$ & 0.5732 & 0.2754 & 0.9647 & 7 \\
$\mathrm{~A}_{8}$ & 0.6143 & 0.2745 & 0.9983 & 8 \\
\hline
\end{tabular}

For employing fuzzy VIKOR method, the criteria values for all the grinding wheel abrasive materials are first converted into the corresponding triangular fuzzy numbers considering $8-20 \%$ of fuzziness in 
the material property values. The developed fuzzy decision matrix is shown in Table 5 . Table 6 provides the corresponding $S_{i}, R_{i}$ and $Q_{i}$ values as calculated using Eqs. (9-15). The related defuzzification is based on centroid method (Vahdani et al., 2011). From Table 6, it is observed that synthetic polycrystal diamond and yttria stabilized zirconia are respectively the best and the worst grinding wheel abrasive materials. The entire ranking preorder for the considered alternatives is found as $A_{5}-A_{3}-A_{2}-A_{4}-A_{6}-A_{1}-$ $\mathrm{A}_{7}-\mathrm{A}_{8}$. There is only a slight difference in this ranking order as compared to that derived using FTOPSIS method. A critical review on the effect of changing $v$ values on the ranking performance of fuzzy VIKOR method shows that the positions of the best and the worst grinding wheel abrasive materials remain unaltered, although there are minor variations in the intermediate ranking positions of the considered alternatives.

While solving the same problem using regret theory-based VIKOR method, the corresponding values of $S_{i}, R_{i}$ and $Q_{i}$ are calculated, as shown in Table 7. From this table, the ranking of the alternative grinding wheel abrasive materials is observed as $\mathrm{A}_{5}-\mathrm{A}_{3}-\mathrm{A}_{4}-\mathrm{A}_{6}-\mathrm{A}_{2}-\mathrm{A}_{1}-\mathrm{A}_{7}-\mathrm{A}_{8}$. It is interesting to notice that also in regret theory-based VIKOR method, the positions of the best two and the worst two material alternatives remain unaltered. There is a slight variation in the intermediate ranking of the considered alternatives. The effects of changing $v$ values on the ranking pattern of the grinding wheel abrasive materials are exhibited in Table 8 . It becomes clear from the table that variations in $v$ values cannot alter the positions of the best and the worst alternatives in the ranking list. The ranking of the alternative grinding wheel abrasive materials as derived using modified VIKOR method is provided in Table 9. The ranking order is observed as $\mathrm{A}_{5}-\mathrm{A}_{3}-\mathrm{A}_{2}-\mathrm{A}_{6}-\mathrm{A}_{4}-\mathrm{A}_{1}-\mathrm{A}_{7}-\mathrm{A}_{8}$. In this method, there is also no change in the positions of the best and the worst ranked materials in the list. When the effects of changing $v$ values on the ranking performance of modified VIKOR method are studied, it is again observed that the positions of the best and the worst ranked materials remain unaltered for different $v$ values. There is a slight variation in the intermediate rankings of the considered alternatives. Lastly, when the interval VIKOR method is employed to solve this material selection problem, the original decision matrix is first converted into another evaluation matrix, as shown in Table 10, where all the criteria values for the alternatives are expressed in the form of intervals considering $10 \%$ variations in the data. Now employing Eqs. (27-30), the minimum and the maximum values of $S_{i}$ and $R_{i}$ are computed as provided in Table 11. The derived ranking of the grinding wheel abrasive materials using interval VIKOR method is shown in Table 12. The attained ranking pattern is $A_{5}-A_{3}-A_{4}-A_{2}-A_{1}-A_{6}-A_{8}-A_{7}$. In this method, synthetic polycrystal diamond and boron carbide respectively occupy the best and the worst positions in the ranking list. Yttria stabilized zirconia, which is derived as the worst grinding wheel abrasive material in all other VIKOR methods, here becomes a better alternative than the worst choice. The variations in the ranking patterns with respect to changes in $v$ values are exhibited in Table 13 and it is quite interesting to notice that the performance of interval VIKOR method is seriously affected at lower $v$ values. At $v$ value of 0.1 , the best performing material alternative (synthetic polycrystal diamond) even becomes the worst chosen material. After a $v$ value of 0.5 , the ranking patterns become stable and the ranking of the alternatives is observed as expected. In this method, the position of the worst material remains almost unaltered for different $v$ values.

A comparison between the ranking patterns as obtained employing all these six VIKOR methods is provided in Table 14. Based on Spearman's rank correlation coefficient values, it becomes noticeable that the performances of original VIKOR and fuzzy VIKOR, and comprehensive and modified VIKOR methods are exactly the same. On the other hand, interval VIKOR method performs unsatisfactorily when its performance is compared with that of other VIKOR methods. Using Spearman's rank correlation coefficient values, the ranking performance of all the six types of VIKOR method is again compared with the original ranking pattern as derived using FTOPSIS method. In Fig. 1, it is observed that for lower $v$ values, the performance of interval VIKOR method is not at all satisfactory. The ranking performance of modified VIKOR method is the best over all the $v$ values. With increasing $v$ values, the performance of all the variants of VIKOR method becomes quite comparable with that of FTOPSIS method. But still, interval VIKOR method lags behind its counterparts for higher $v$ values. 
Table 5

Fuzzy decision matrix for grinding wheel abrasive material selection problem

\begin{tabular}{cccccccc}
\hline Alternative & $\mathrm{C}_{1}$ & $\mathrm{C}_{2}$ & $\mathrm{C}_{3}$ & $\mathrm{C}_{4}$ & $\mathrm{C}_{5}$ & $\mathrm{C}_{6}$ & $\mathrm{C}_{7}$ \\
\hline $\mathrm{A}_{1}$ & $(2700,3200,3700)$ & $(391,451,511)$ & $(2925,3475,4025)$ & $(581,756,931)$ & $(12,17,22)$ & $(2.65,4.15,5.65)$ & $(12,18,24)$ \\
$\mathrm{A}_{2}$ & $(2000,2400,2800)$ & $(590,690,790)$ & $(4275,4975,5675)$ & $(1099,1324,1549)$ & $(68,98,128)$ & $(2.2,3,3.8)$ & $(45,60,75)$ \\
$\mathrm{A}_{3}$ & $(4400,5000,5600)$ & $(725,850,975)$ & $(6000,6900,7800)$ & $(1282,1532,1782)$ & $(9,13,17)$ & $(3.55,4.5,5.45)$ & $(714,864,1014)$ \\
$\mathrm{A}_{4}$ & $(2600,3000,3400)$ & $(350,400,450)$ & $(3200,3800,4400)$ & $(729,879,1029)$ & $(21,30,39)$ & $(3.15,4,4.85)$ & $(107,152,197)$ \\
$\mathrm{A}_{5}$ & $(7300,8000,8700)$ & $(818,953,1088)$ & $(5900,6700,7500)$ & $(4188,4688,5188)$ & $(950,1200,1450)$ & $(6.45,8.6,10.8)$ & $(1050,1300,1550)$ \\
$\mathrm{A}_{6}$ & $(2150,2550,2950)$ & $(370,440,510)$ & $(3950,4600,5250)$ & $(400,480,560)$ & $(150,200,250)$ & $(2.6,3.1,3.6)$ & $(6.5,10,13.5)$ \\
$\mathrm{A}_{7}$ & $(2400,2800,3200)$ & $(385,460,535)$ & $(1421,1721,2021)$ & $(425,600,775)$ & $(55,90,125)$ & $(1.95,2.5,3.05)$ & $(36,50,64)$ \\
$\mathrm{A}_{8}$ & $(900,1200,1500)$ & $(115,160,205)$ & $(1350,1750,2150)$ & $(495,620,745)$ & $(1.4,2.2,3)$ & $(5.75,8.2,10.7)$ & $(33,45,57)$ \\
\hline
\end{tabular}

Table 6

Ranking of material alternatives in fuzzy VIKOR method

\begin{tabular}{ccccc}
\hline Alternative & $S_{i}$ & $R_{i}$ & $Q_{i}$ & Rank \\
\hline $\mathrm{A}_{1}$ & 0.5875 & 0.2415 & 0.6846 & 6 \\
$\mathrm{~A}_{2}$ & 0.4954 & 0.2550 & 0.6512 & 3 \\
$\mathrm{~A}_{3}$ & 0.2159 & 0.1366 & 0.2879 & 2 \\
$\mathrm{~A}_{4}$ & 0.5703 & 0.2386 & 0.6695 & 4 \\
$\mathrm{~A}_{5}$ & -0.0179 & 0.0473 & 0 & 1 \\
$\mathrm{~A}_{6}$ & 0.5470 & 0.2482 & 0.6711 & 5 \\
$\mathrm{~A}_{7}$ & 0.7263 & 0.3498 & 0.9463 & 7 \\
$\mathrm{~A}_{8}$ & 0.8110 & 0.3492 & 0.9964 & 8 \\
\hline
\end{tabular}

\section{Table 7}

Ranking of material alternatives in regret theory-based VIKOR method

\begin{tabular}{ccccc}
\hline Alternative & $S_{i}$ & $R_{i}$ & $Q_{i}$ & Rank \\
\hline $\mathrm{A}_{1}$ & 1047.6282 & 0.2881 & 0.5487 & 6 \\
$\mathrm{~A}_{2}$ & 818.9093 & 0.2925 & 0.5044 & 5 \\
$\mathrm{~A}_{3}$ & 214.2776 & 0.1567 & 0.2109 & 2 \\
$\mathrm{~A}_{4}$ & 968.0284 & 0.2612 & 0.4993 & 3 \\
$\mathrm{~A}_{5}$ & 12.4457 & 0.0168 & 0 & 1 \\
$\mathrm{~A}_{6}$ & 840.3884 & 0.2847 & 0.4997 & 4 \\
$\mathrm{~A}_{7}$ & 1788.0339 & 0.4356 & 0.8857 & 7 \\
$\mathrm{~A}_{8}$ & 2314.0205 & 0.4332 & 0.9971 & 8 \\
\hline
\end{tabular}

\section{Table 8}

Change of ranking patterns with varying $v$ values in regret theory-based VIKOR method

\begin{tabular}{cccccccccc}
\hline Alternative & $v=0.1$ & $v=0.2$ & $v=0.3$ & $v=0.4$ & $v=0.5$ & $v=0.6$ & $v=0.7$ & $v=0.8$ & $v=0.9$ \\
\hline $\mathrm{A}_{1}$ & $0.6279(6)$ & $0.6081(6)$ & $0.5883(6)$ & $0.5685(6)$ & $0.5487(6)$ & $0.5290(6)$ & $0.5092(6)$ & $0.4894(6)$ & $0.4696(6)$ \\
$\mathrm{A}_{2}$ & $0.6275(5)$ & $0.5967(5)$ & $0.5660(5)$ & $0.5352(5)$ & $0.5044(5)$ & $0.4736(4)$ & $0.4428(3)$ & $0.4120(3)$ & $0.3812(3)$ \\
$\mathrm{A}_{3}$ & $0.3094(2)$ & $0.2848(2)$ & $0.2601(2)$ & $0.2355(2)$ & $0.2109(2)$ & $0.1862(2)$ & $0.1616(2)$ & $0.1370(2)$ & $0.1123(2)$ \\
$\mathrm{A}_{4}$ & $0.5667(3)$ & $0.5498(3)$ & $0.5330(3)$ & $0.5162(3)$ & $0.4993(3)$ & $0.4825(5)$ & $0.4657(5)$ & $0.4488(5)$ & $0.4320(5)$ \\
$\mathrm{A}_{5}$ & $0(1)$ & $0(1)$ & $0(1)$ & $0(1)$ & $0(1)$ & $0(1)$ & $0(1)$ & $0(1)$ & $0(1)$ \\
$\mathrm{A}_{6}$ & $0.6116(4)$ & $0.5836(4)$ & $0.5557(4)$ & $0.5277(4)$ & $0.4997(4)$ & $0.4717(3)$ & $0.4437(4)$ & $0.4157(4)$ & $0.3877(4)$ \\
$\mathrm{A}_{7}$ & $0.9771(7)$ & $0.9543(7)$ & $0.9314(7)$ & $0.9086(7)$ & $0.8857(7)$ & $0.8629(7)$ & $0.8400(7)$ & $0.8172(7)$ & $0.7943(7)$ \\
$\mathrm{A}_{8}$ & $0.9948(8)$ & $0.9953(8)$ & $0.9959(8)$ & $0.9965(8)$ & $0.9971(8)$ & $0.9977(8)$ & $0.9983(8)$ & $0.9988(8)$ & $0.9994(8)$ \\
\hline
\end{tabular}

Table 9

Ranking of material alternatives in modified VIKOR method

\begin{tabular}{ccccc}
\hline Alternative & $E_{i}$ & $F_{i}$ & $P_{i}$ & Rank \\
\hline $\mathrm{A}_{1}$ & 0.7236 & 0.9938 & 0.8587 & 6 \\
$\mathrm{~A}_{2}$ & 0.6076 & 0.9612 & 0.7844 & 3 \\
$\mathrm{~A}_{3}$ & 0.2804 & 0.9910 & 0.6357 & 2 \\
$\mathrm{~A}_{4}$ & 0.7030 & 0.9768 & 0.8399 & 5 \\
$\mathrm{~A}_{5}$ & 0.0168 & 0.0386 & 0.0277 & 1 \\
$\mathrm{~A}_{6}$ & 0.6694 & 1.0000 & 0.8347 & 4 \\
$\mathrm{~A}_{7}$ & 0.8946 & 1.0000 & 0.9473 & 7 \\
$\mathrm{~A}_{8}$ & 0.9925 & 1.0000 & 0.9963 & 8 \\
\hline
\end{tabular}


Table 10

Decision matrix for interval VIKOR method

\begin{tabular}{ccccccccccccccc}
\hline Alternative & \multicolumn{2}{c}{$\mathrm{C}_{1}$} & \multicolumn{2}{c}{$\mathrm{C}_{2}$} & \multicolumn{2}{c}{$\mathrm{C}_{3}$} & \multicolumn{2}{c}{$\mathrm{C}_{4}$} & \multicolumn{3}{c}{$\mathrm{C}_{5}$} & \multicolumn{2}{c}{$\mathrm{C}_{6}$} & $\mathrm{C}_{7}$ \\
\hline 1 & 2880 & 3520 & 405.9 & 496.1 & 3127.5 & 3822.5 & 680.4 & 831.6 & 15.3 & 18.7 & 3.735 & 4.565 & 16.2 & 19.8 \\
2 & 2160 & 2640 & 621 & 759 & 4477.5 & 5472.5 & 1191.6 & 1456.4 & 88.2 & 107.8 & 2.7 & 3.3 & 54 & 66 \\
3 & 4500 & 5500 & 765 & 935 & 6210 & 7590 & 1378.8 & 1685.2 & 11.7 & 14.3 & 4.05 & 4.95 & 777.6 & 950.4 \\
4 & 2700 & 3300 & 360 & 440 & 3420 & 4180 & 791.1 & 966.9 & 27 & 33 & 3.6 & 4.4 & 136.8 & 167.2 \\
5 & 7200 & 8800 & 857.7 & 1048.3 & 6030 & 7370 & 4219.2 & 5156.8 & 1080 & 1320 & 7.74 & 9.46 & 1170 & 1430 \\
6 & 2295 & 2805 & 396 & 484 & 4140 & 5060 & 432 & 528 & 180 & 220 & 2.79 & 3.41 & 9 & 11 \\
7 & 2520 & 3080 & 414 & 506 & 1548.9 & 1893.1 & 540 & 660 & 81 & 99 & 2.25 & 2.75 & 45 & 55 \\
8 & 1080 & 1320 & 144 & 176 & 1575 & 1925 & 558 & 682 & 1.98 & 2.42 & 7.38 & 9.02 & 40.5 & 49.5 \\
\hline
\end{tabular}

Table 11

$S_{i}$ and $R_{i}$ values for interval VIKOR method

\begin{tabular}{ccccc} 
Alternative & \multicolumn{2}{c}{$S_{i}$} & \multicolumn{3}{c}{$R_{i}$} \\
\cline { 2 - 5 } & $L$ & $U$ & $L$ & $U$ \\
$\mathrm{~A}_{1}$ & 0.5379 & 0.5925 & 0.1136 & 0.1139 \\
$\mathrm{~A}_{2}$ & 0.4876 & 0.5528 & 0.1108 & 0.1216 \\
$\mathrm{~A}_{3}$ & 0.4244 & 0.5304 & 0.1140 & 0.1142 \\
$\mathrm{~A}_{4}$ & 0.5518 & 0.6087 & 0.1123 & 0.1129 \\
$\mathrm{~A}_{5}$ & 0.1204 & 0.2974 & 0.1160 & 0.1420 \\
$\mathrm{~A}_{6}$ & 0.5360 & 0.5907 & 0.1170 & 0.1200 \\
$\mathrm{~A}_{7}$ & 0.6143 & 0.6561 & 0.1207 & 0.1297 \\
$\mathrm{~A}_{8}$ & 0.5778 & 0.6261 & 0.1150 & 0.1189 \\
\hline
\end{tabular}

Table 12

$Q$ interval numbers and mid-point $m(E)$ values with rank

\begin{tabular}{|c|c|c|c|c|}
\hline Alternative & & & $m(E)$ & Rank \\
\hline $\mathrm{A}_{1}$ & 0.4340 & 0.4897 & 0.4619 & 5 \\
\hline $\mathrm{A}_{2}$ & 0.3427 & 0.5767 & 0.4597 & 4 \\
\hline $\mathrm{A}_{3}$ & 0.3343 & 0.4368 & 0.3855 & 2 \\
\hline $\mathrm{A}_{4}$ & 0.4270 & 0.4885 & 0.4577 & 3 \\
\hline $\mathrm{A}_{5}$ & 0.0833 & 0.6652 & 0.3742 & 1 \\
\hline $\mathrm{A}_{6}$ & 0.4864 & 0.5861 & 0.5362 & 6 \\
\hline $\mathrm{A}_{7}$ & 0.6197 & 0.8030 & 0.7113 & 8 \\
\hline $\mathrm{A}_{8}$ & 0.4941 & 0.6010 & 0.5475 & 7 \\
\hline
\end{tabular}

Table 13

Changes in ranking patterns with varying $v$ values in interval VIKOR method

\begin{tabular}{cccccccccc}
\hline Alternative & $v=0.1$ & $v=0.2$ & $v=0.3$ & $v=0.4$ & $v=0.5$ & $v=0.6$ & $v=0.7$ & $v=0.8$ & $v=0.9$ \\
\hline $\mathrm{A}_{1}$ & 3 & 3 & 3 & 3 & 5 & 4 & 4 & 4 & 4 \\
$\mathrm{~A}_{2}$ & 4 & 4 & 4 & 4 & 4 & 3 & 3 & 3 & 3 \\
$\mathrm{~A}_{3}$ & 2 & 1 & 1 & 1 & 2 & 2 & 2 & 2 & 2 \\
$\mathrm{~A}_{4}$ & 1 & 2 & 2 & 2 & 3 & 5 & 5 & 5 & 6 \\
$\mathrm{~A}_{5}$ & 8 & 7 & 7 & 5 & 1 & 1 & 1 & 1 & 1 \\
$\mathrm{~A}_{6}$ & 6 & 6 & 6 & 7 & 6 & 6 & 6 & 6 & 5 \\
$\mathrm{~A}_{7}$ & 7 & 8 & 8 & 8 & 8 & 8 & 8 & 8 & 8 \\
$\mathrm{~A}_{8}$ & 5 & 5 & 5 & 6 & 7 & 7 & 7 & 7 & 7 \\
\hline
\end{tabular}

Table 14

Comparison of ranking patterns for VIKOR method and its variants

\begin{tabular}{ccccccc}
\hline Method & $\begin{array}{c}\text { Original } \\
\text { VIKOR }\end{array}$ & $\begin{array}{c}\text { Comprehensive } \\
\text { VIKOR }\end{array}$ & $\begin{array}{c}\text { Fuzzy } \\
\text { VIKOR }\end{array}$ & $\begin{array}{c}\text { Regret } \\
\text { VIKOR }\end{array}$ & $\begin{array}{c}\text { Modified } \\
\text { VIKOR }\end{array}$ & $\begin{array}{c}\text { Interval } \\
\text { VIKOR }\end{array}$ \\
\hline Original VIKOR & & 0.976 & 1.000 & 0.929 & 0.976 & 0.929 \\
Comprehensive VIKOR & & & 0.976 & 0.905 & 1.000 & 0.857 \\
Fuzzy VIKOR & & & & 0.929 & 0.976 & 0.929 \\
Regret VIKOR & & & & & 0.905 & 0.905 \\
Modified VIKOR & & & & & & 0.857 \\
\hline
\end{tabular}




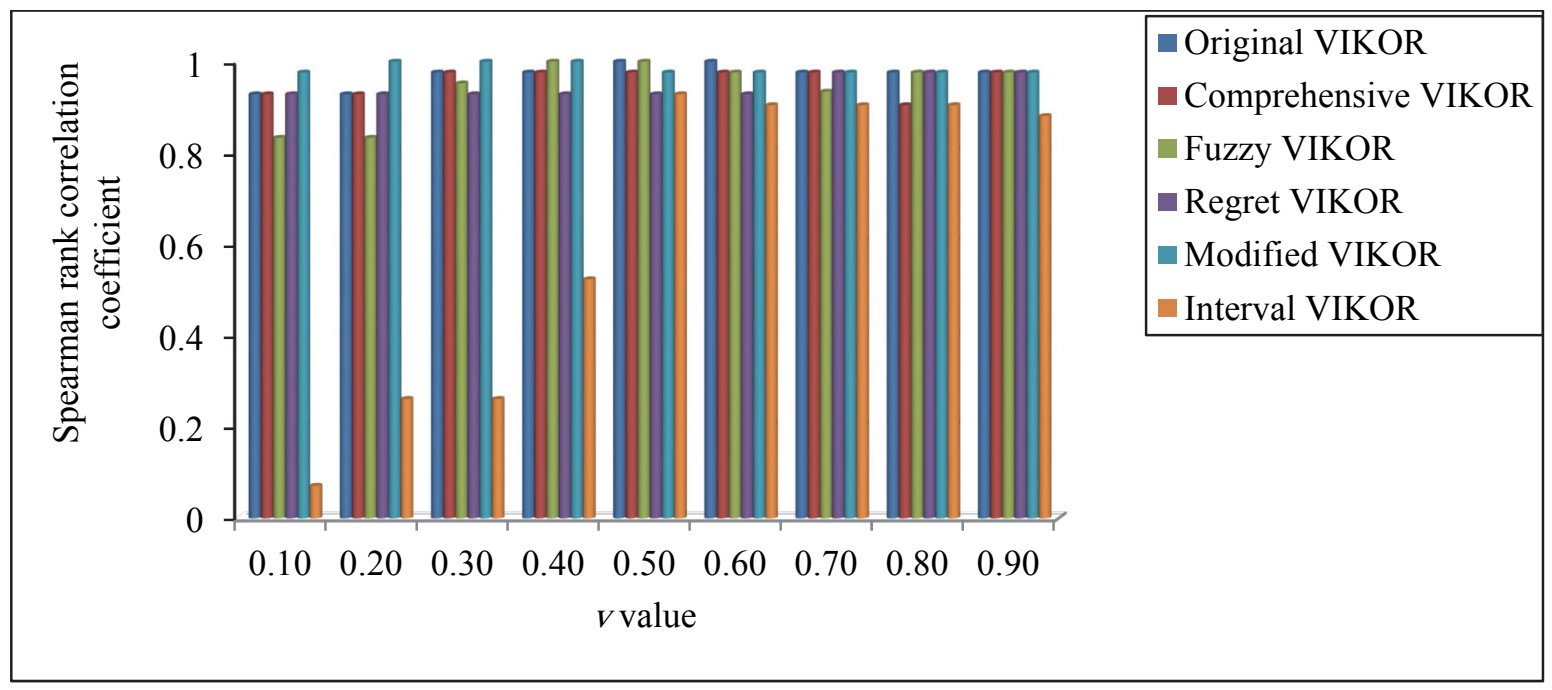

Fig. 1 Ranking performance of VIKOR method and its variants for changing $v$ values in Example 1

\subsection{Example 2}

Sun (2002) applied data envelopment analysis (DEA) to evaluate $21 \mathrm{CNC}$ machine tools with respect to system specifications and cost at the operational level. The evaluation of CNC machines was based on the combination of the Banker, Charnes and Cooper (BCC) model and cross efficiency method of DEA. It was aimed at identifying a homogenous set of good systems, by measuring, for each machine, the pure technical efficiency through the BCC model and thus, YANG ML-15A, YCM-TC-15, VTURN 16, EX-106, ECOCA SJ20, FEMCO, WNCL-30, TOPPER TNL-85A, -85T and -100AL, ATECH MT52L, $-75 \mathrm{~S}$ and $-75 \mathrm{~L}$ were identified as the 'best performance' machine tools. Seven criteria, i.e. capital cost (CC) (in NT\$), spindle speed range (SS) (in rpm), tool capacity (TC), rapid traverse rate of X-axis (TX) (in $\mathrm{m} / \mathrm{min}$ ), rapid traverse rate of $\mathrm{Z}$-axis (TZ) (in $\mathrm{m} / \mathrm{min}$ ), maximum machining diameter (MD) (in $\mathrm{mm}$ ) and maximum machining length (ML) (in $\mathrm{mm}$ ) were considered to affect the ability of a CNC machine to perform its various machining operations. Among those seven criteria, CC, TX and TZ are non-beneficial attributes as their lower values are desirable. On the other hand, SS, TC, MD and ML are beneficial attributes where their higher values are always preferable. In order to determine the relative importance (weight) of each criterion affecting $\mathrm{CNC}$ machine tool selection decision, the criteria weights are determined using analytic hierarchy process as $w_{\mathrm{CC}}=0.1148, w_{\mathrm{SS}}=0.1808, w_{\mathrm{TC}}=$ $0.1884, w_{\mathrm{TX}}=0.1197, w_{\mathrm{TZ}}=0.1148, w_{\mathrm{MD}}=0.1546$ and $w_{\mathrm{ML}}=0.1268$. The original decision matrix for this CNC machine tool selection problem is given in Table 15. As Sun (2002) did not derive a complete ranking of the considered CNC machine tools, the performance of VIKOR method and its variants cannot be compared because there is no benchmark solution. Thus, in order to judge the ranking performance of different variants of VIKOR method, the ranking pattern of $21 \mathrm{CNC}$ machine tools as obtained using the original VIKOR method in Table 16 is considered here as the benchmark solution. While applying the original VIKOR method, the ranking of all the CNC machine tools is obtained as VTURN 16>YCM TC-15>ATECH MT-52L $>$ ECOCA SJ25>ATECH MT-75L $>$ FEMCO WNCL30 $>$ FEMCO WNCL-20 $>$ ATECH MT-75S $>$ ECCOA SJ30 $>$ ATECH MT-52S $>$ EX-106 $>$ FEMCO HL15 $>$ TOPPER TNL-85T $>$ TOPPER TNL-100T $>$ TOPPER TNL-100AL $>$ TOPPER TNL-120T $>$ YANG ML-25A > YANG ML-15A>ECOCA SJ20>TOPPER TNL-85A>TOPPER TNL-100A. A study on the ranking performance of the original VIKOR method with respect to changing $v$ values depicts that variation in $v$ values does not seriously affect the positions of the best and the work ranked CNC machine tools in the derived ranking lists. Table 17 shows the ranking patterns of the alternative CNC machine tools as attained while employing the considered variants of VIKOR method. In Fig. 2, the ranking patterns of all the five variants of VIKOR method are compared with that of the original VIKOR method at different $v$ values. At lower $v$ values, interval VIKOR method is the worst performer and after $v=0.5$, its performance becomes quite stable. On the other hand, the reverse phenomenon is 
exactly noticed in case of regret theory-based VIKOR method. At higher $v$ values, its ranking performance is extremely poor although it exhibits a satisfactory performance at lower $v$ values. The performances of comprehensive, fuzzy and modified VIKOR methods are almost similar to that of the original VIKOR method.

Table 15

Quantitative data for machine tool selection problem (Sun, 2002)

\begin{tabular}{ccccccccc}
\hline Sl. No. & CNC lathe & CC & SS & TC & TX & TZ & MD & ML \\
\hline 1 & YANG ML-15A & 1200000 & 5590 & 8 & 24 & 24 & 205 & 350 \\
2 & YANG ML-25A & 1550000 & 3465 & 8 & 20 & 20 & 280 & 520 \\
3 & YCM TC-15 & 1400000 & 5950 & 12 & 15 & 20 & 250 & 469 \\
4 & VTURN 16 & 1100000 & 5940 & 12 & 12 & 15 & 230 & 600 \\
5 & FEMCO HL-15 & 1200000 & 5940 & 12 & 12 & 16 & 150 & 330 \\
6 & FEMCO WNCL-20 & 1500000 & 3465 & 12 & 6 & 12 & 260 & 420 \\
7 & FEMCO WNCL-30 & 2600000 & 3960 & 12 & 12 & 16 & 300 & 625 \\
8 & EX-106 & 1320000 & 4950 & 12 & 24 & 30 & 240 & 340 \\
9 & ECOCA SJ20 & 1180000 & 4480 & 8 & 24 & 24 & 250 & 330 \\
10 & ECOCA SJ25 & 1550000 & 3950 & 12 & 15 & 20 & 280 & 460 \\
11 & ECCOA SJ30 & 1600000 & 3450 & 12 & 15 & 20 & 280 & 460 \\
12 & TOPPER TNL-85A & 1200000 & 3465 & 8 & 20 & 24 & 264 & 400 \\
13 & TOPPER TNL-100A & 1350000 & 2970 & 8 & 20 & 24 & 264 & 400 \\
14 & TOPPER TNL-100AL & 1400000 & 2970 & 12 & 24 & 30 & 300 & 600 \\
15 & TOPPER TNL-85T & 1350000 & 3465 & 12 & 30 & 30 & 264 & 350 \\
16 & TOPPER TNL-100T & 1450000 & 2970 & 12 & 20 & 24 & 300 & 400 \\
17 & TOPPER TNL-120T & 1520000 & 2475 & 12 & 20 & 24 & 300 & 400 \\
18 & ATECH MT-52S & 1376000 & 4752 & 12 & 20 & 24 & 235 & 350 \\
19 & ATECH MT-52L & 1440000 & 4752 & 12 & 20 & 24 & 235 & 600 \\
20 & ATECH MT-75S & 1824000 & 3790 & 10 & 12 & 20 & 300 & 530 \\
21 & ATECH MT-75L & 1920000 & 3790 & 10 & 12 & 20 & 300 & 1030 \\
\hline
\end{tabular}

Table 16

Ranking of CNC machine tools using original VIKOR method

\begin{tabular}{cccccc}
\hline Sl. No. & CNC lathe & $S_{i}$ & $R_{i}$ & $Q_{i}$ & Rank \\
\hline 1 & YANG ML-15A & 0.6022 & 0.1884 & 0.9370 & 18 \\
2 & YANG ML-25A & 0.5860 & 0.1884 & 0.9195 & 17 \\
3 & YCM TC-15 & 0.2720 & 0.1016 & 0.1860 & 2 \\
4 & VTURN 16 & 0.1996 & 0.0779 & 0.0000 & 1 \\
5 & FEMCO HL-15 & 0.3450 & 0.1546 & 0.5047 & 12 \\
6 & FEMCO WNCL-20 & 0.3117 & 0.1293 & 0.3543 & 7 \\
7 & FEMCO WNCL-30 & 0.3472 & 0.1148 & 0.3274 & 6 \\
8 & EX-106 & 0.4603 & 0.1250 & 0.4960 & 11 \\
9 & ECOCA SJ20 & 0.6157 & 0.1884 & 0.9516 & 19 \\
10 & ECOCA SJ25 & 0.3583 & 0.1041 & 0.2907 & 4 \\
11 & ECCOA SJ30 & 0.3882 & 0.1301 & 0.4408 & 9 \\
12 & TOPPER TNL-85A & 0.6230 & 0.1884 & 0.9596 & 20 \\
13 & TOPPER TNL-100A & 0.6602 & 0.1884 & 1.0000 & 21 \\
14 & TOPPER TNL-100AL & 0.4605 & 0.1551 & 0.6324 & 15 \\
15 & TOPPER TNL-85T & 0.5432 & 0.1293 & 0.6056 & 13 \\
16 & TOPPER TNL-100T & 0.4424 & 0.1551 & 0.6127 & 14 \\
17 & TOPPER TNL-120T & 0.4735 & 0.1808 & 0.7630 & 16 \\
18 & ATECH MT-52S & 0.4200 & 0.1232 & 0.4441 & 10 \\
19 & ATECH MT-52L & 0.3796 & 0.0779 & 0.1954 & 3 \\
20 & ATECH MT-75S & 0.4336 & 0.1124 & 0.4101 & 8 \\
21 & ATECH MT-75L & 0.3504 & 0.1124 & 0.3198 & 5 \\
\hline
\end{tabular}




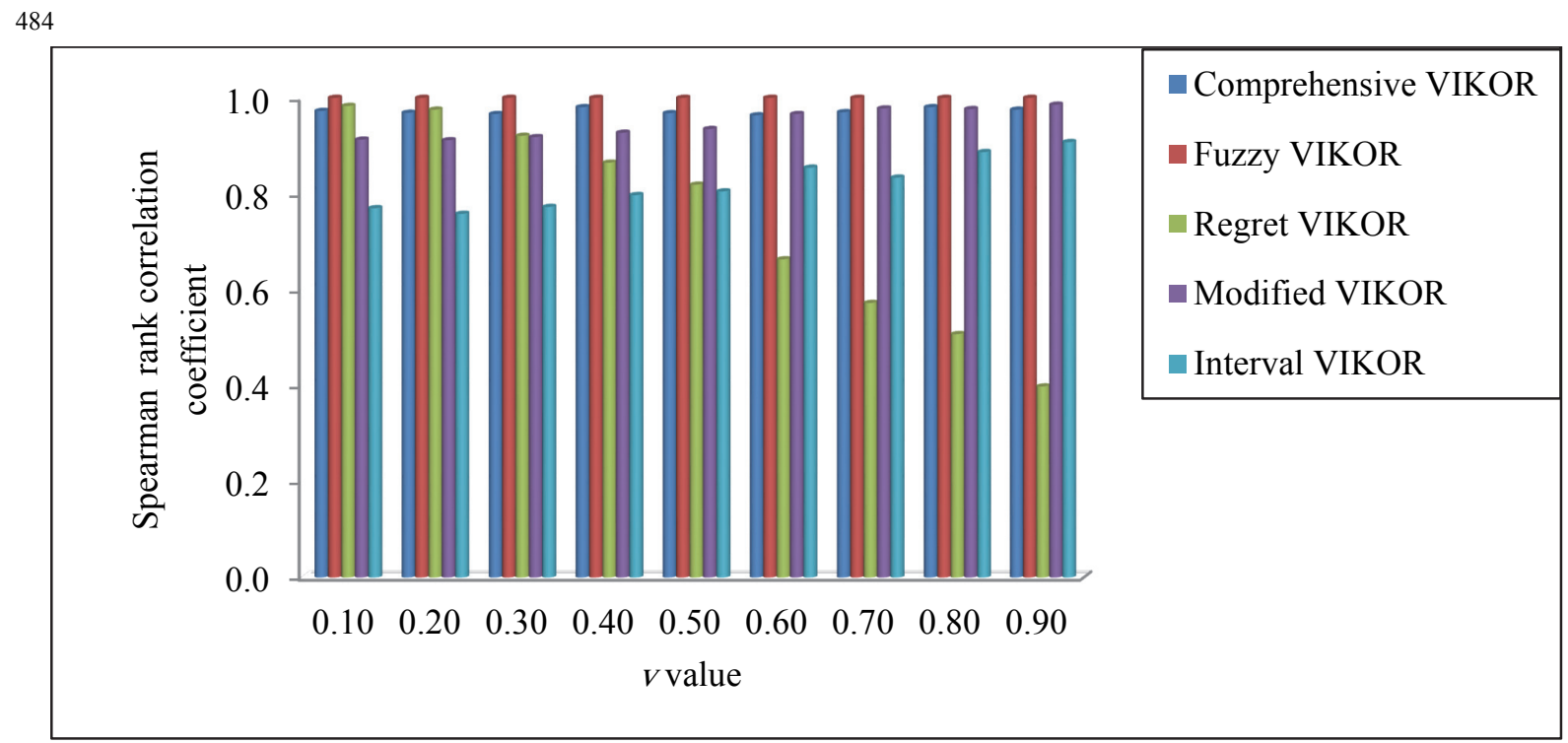

Fig. 2 Ranking performance of VIKOR method and its variants for changing $v$ values in Example 2

Table 17

Rankings of CNC machine tools using VIKOR method and its variants

\begin{tabular}{cccccc}
\hline VIKOR & $\begin{array}{c}\text { Comprehensive } \\
\text { VIKOR }\end{array}$ & $\begin{array}{c}\text { Fuzzy } \\
\text { VIKOR }\end{array}$ & $\begin{array}{c}\text { Regret theory-based } \\
\text { VIKOR }\end{array}$ & $\begin{array}{c}\text { Modified } \\
\text { VIKOR }\end{array}$ & $\begin{array}{c}\text { Interval } \\
\text { VIKOR }\end{array}$ \\
\hline 18 & 17 & 18 & 19 & 18 & 12 \\
17 & 19 & 17 & 16 & 17 & 14 \\
2 & 2 & 2 & 7 & 4 & 2 \\
1 & 1 & 1 & 12 & 1 & 1 \\
12 & 9 & 12 & 17 & 7 & 18 \\
7 & 6 & 7 & 9 & 11 & 5 \\
6 & 4 & 6 & 2 & 13 & 10 \\
11 & 10 & 11 & 5 & 19 & 13 \\
19 & 18 & 19 & 21 & 6 & 6 \\
4 & 5 & 4 & 6 & 8 & 9 \\
9 & 12 & 9 & 8 & 20 & 15 \\
20 & 20 & 20 & 20 & 21 & 20 \\
21 & 21 & 21 & 18 & 14 & 19 \\
15 & 15 & 15 & 14 & 9 & 17 \\
13 & 14 & 13 & 11 & 15 & 21 \\
14 & 13 & 14 & 13 & 12 & 8 \\
16 & 16 & 16 & 15 & 3 & 3 \\
10 & 8 & 10 & 10 & 5 & 7 \\
3 & 3 & 3 & 1 & 2 & 4 \\
8 & 11 & 8 & 4 & & \\
5 & 7 & 5 & 3 & & 16 \\
\hline
\end{tabular}

\section{Conclusions}

The VIKOR method has become quite popular among the decision making community due to its computational simplicity and capability of providing almost accurate results. Other variants of VIKOR method have also been subsequently developed to fulfill the typical requirements of the decision makers. In this paper, using two demonstrative examples, the ranking performance of VIKOR method and its five variants is analyzed. Amongst the six different types of VIKOR method, the performances of interval and regret theory-based VIKOR method are unsatisfactory. For these two variants of VIKOR method, changes in $v$ values also seriously affect their ranking patterns. It is observed that original VIKOR and fuzzy VIKOR, and comprehensive and modified VIKOR methods behave similarly. When 
the criteria values for the alternatives are vague and imprecise, the application of fuzzy VIKOR method is thus preferred to interval VIKOR method.

\section{References}

Anojkumar, L., Ilangkumaran, M., \& Sasirekha, V. (2014). Comparative analysis of MCDM methods for pipe material selection in sugar industry. Expert Systems with Applications, 41(6), 2964-2980.

Bahraminasab, M., \& Jahan, A. (2011). Material selection for femoral component of total knee replacement using comprehensive VIKOR. Materials and Design, 32(8-9), 4471-4477.

Bell, D.E. (1982). Regret in decision making under uncertainty. Operations Research, 30, 961-981.

Cavallini, C., Giorgetti, A., Citti, P., \& Nicolaie, F. (2013). Integral aided method for material selection based on quality function deployment and comprehensive VIKOR algorithm. Materials and Design, 47, 27-34.

Chatterjee, P., Athawale, V.M., \& Chakraborty, S. (2009). Selection of materials using compromise ranking and outranking methods. Materials and Design, 30(10), 4043-4053.

Delgado, M., Vila, M.A., \& Voxman, W. (1998). On a canonical representation of fuzzy numbers. Fuzzy Sets and Systems, 94(1), 205-216.

Huang, J-J., Tzeng, G-H., \& Liu, H-H. (2009). A revised VIKOR model for multiple criteria decision making - The perspective of regret theory. In: MCDM 2009, Shi, Y. et al. (Eds.), 761-768.

Jahan, A., Mustapha, F., Ismail, M.Y., Sapuan, S.M., \& Bahraminasab, M. (2011). A comprehensive VIKOR method for material selection. Materials and Design, 32(3), 1215-1221.

Jahanshahloo, G.R., Lotfi, F.H. \& Davoodi, A.R. (2009). Extension of TOPSIS for decision-making problems with interval data: Interval efficiency. Mathematical and Computer Modelling, 49(5-6), 1137-1142.

Jeya Girubha, R., \& Vinodh, S. (2012). Application of fuzzy VIKOR and environmental impact analysis for material selection of an automotive component. Materials and Design, 37, 478-486.

Kuo, M-S., \& Liang, G-S. (2011). Combining VIKOR with GRA techniques to evaluate service quality of airports under fuzzy environment. Expert Systems with Applications, 38(3), 1304-1312.

Liou, J.J.H., Tsai, C-Y., Lin, R-H., \& Tzeng, G-H. (2011). A modified VIKOR multiple-criteria decision method for improving domestic airlines service quality. Journal of Air Transport Management, 17(2), 57-61.

Maity, S.R., \& Chakraborty, S, (2013). Grinding wheel abrasive material selection using fuzzy TOPSIS method. Materials and Manufacturing Processes, 28(4), 408-417.

Maji, L. (2012). A note on "A modified VIKOR multiple-criteria decision method for improving domestic airlines service quality". Journal of Air Transport Management, 20, 7-8.

Mardani, A., Zavadskas, E.K., Govindan, K., Senin, A.A., \& Jusoh, A., (2016). VIKOR technique: A systematic review of the state of the art literature on methodologies and applications. Sustainability, $8,1-38$.

Mellers, B.A. (2000). Choice and the relative pleasure of consequences. Psychological Bulletin, 126, 910-924.

Opricovic, S., \& Tzeng, G-H. (2004). Compromise solution by MCDM methods: A comparative analysis of VIKOR and TOPSIS. European Journal of Operational Research, 156(2), 445-455.

Opricovic, S. (2011). Fuzzy VIKOR with an application to water resources planning. Expert Systems with Applications, 38(10), 12983-12990.

Rao, R.V. (2007). Decision Making in the Manufacturing Environment using Graph Theory and Fuzzy Multiple Attribute Decision Making Methods. Springer-Verlag, London.

San Cristóbal, J.R. (2011). Multi-criteria decision-making in the selection of a renewable energy project in Spain: The Vikor method. Renewable Energy, 36(2), 498-502.

Sayadi, M.K., Heydari, M., \& Shahanaghi, K. (2009). Extension of VIKOR method for decision making problem with interval numbers. Applied Mathematical Modelling, 33(5), 2257-2262.

Sengupta, A., \& Pal, T.K. (2000). On comparing interval numbers. European Journal of Operational Research, 127(1), 28-43. 
Sun, S. (2002). Assessing computer numerical control machines using data envelopment analysis. International Journal of Production Research, 40(9), 2011-2039.

Vahdani, B., Mousavi, S.M., \& Tavakkoli-Moghaddam, R. (2011). Group decision making based on novel fuzzy modified TOPSIS method. Applied Mathematical Modelling, 35(9), 4257-4269.

Velasquez, M., \& Hester, P.T. (2013). An analysis of multi-criteria decision making methods. International Journal of Operations Research, 10(2), 56-66.

Yazdani, M., \& Graeml, F.R. (2014). VIKOR and its applications: A state-of-the-art survey. International Journal of Strategic Decision Sciences, 5(2), 56-83.

Zeleny, M. (1982). Multiple Criteria Decision Making. Mc-Graw-Hill, New York. 